Es investigador de la Universidad Autónoma Metropolitana y funcionario del Banco de México. Es licenciado en Relaciones Industriales por la Universidad Iberoamericana, maestro en Economía por El Colegio de México y por la McGill University, Montreal. Algunas de sus publicaciones más recientes son México en Bretton Woods; Banco de México: su historia en cápsulas; Raúl Martínez Ostos: leyes, finanzas y diplomacia para el desarrollo, 1907-1993; Historia del Banco de México, vols. I y II, los cuales son una referencia obligada para los interesados en la historia del Banco de México. Es colaborador del diario El Economista y ha publicado numerosos ensayos, artículos y editoriales periodísticos sobre temas de economía e historia económica de México. 


\title{
Resumen
}

A 25 años de distancia, no contamos con una explicación convincente de por qué tuvo lugar la expropiación bancaria de 1982 . En este trabajo se argumenta que el hecho tuvo su origen en posturas de pensamiento heterodoxas de las cuales derivó una propuesta de política económica alternativa a la que se había aplicado de 1958 a 1970. En general, la nueva propuesta de política económica contenía contradicciones que desembocaron en una crisis cambiaria de gran intensidad. En lo específico, el expansionismo fiscal y monetario implícito en esa política era incompatible con el mantenimiento de la estabilidad cambiaria. En congruencia con las posturas de pensamiento subyacentes en la política económica alternativa que se adoptó, la solución sugerida al presidente López Portillo por sus asesores económicos "reformistas" fue expropiar la banca y aplicar un control integral de cambios.

Palabras clave: Estatización bancaria, México.

\begin{abstract}
25 years have passed since expropriation of private banks was decreed in Mexico in 1982. Since then, no convincing explanations of that decision have been presented. In this paper it is argued that the origins derived from heterodox currents of thought based on which an alternative economic policy was adopted, different to the one applied from 1958 to 1970. In general terms, that alternative economic policy implied strong contradictions, and its application derived in an intense devaluation crisis. Specifically, the fiscal and monetary expansionism implicit in the economic policy adopted, was incompatible with the maintenance of exchange stability. Based also on those heterodox currents of thought, the solutions suggested by his "Reformist" economic advisors to the president Lopez Portillo were to expropriate the private banks and apply a general exchange control.
\end{abstract}

Key words: Bank nationalization, Mexico.

Fecha de recepción: agosto de 2009

Fecha de aceptación: octubre de 2009 


\title{
LA ESTATIZACIÓN BANCARIA EN MÉXICO. UNA INTERPRETACIÓN DESDE LA PERSPECTIVA DEL PENSAMIENTO ECONÓMICO
}

\author{
Eduardo Turrent Díaz
}

\author{
EL MARCO HISTÓRICO
}

$\mathrm{R}$ esulta difícil recrear en retrospectiva el ambiente de crispación intelectual que se vivió hacia finales del sexenio del presidente Gustavo desirolo estabilzador (Der), que se extendió desde medialos de la décadesarrollo estabilizador (DE), que se extendió desde mediados de la década de los cincuenta hasta 1970, en que tomó posesión el presidente Luis Echeverría. Esos años se caracterizaron por una exacerbación de los ánimos en los frentes ideológico y político, quizá estimulada, en ambos casos, por el movimiento estudiantil de 1968 y el trágico desenlace que tuvo. En materia de reflexión económica, en ese periodo se volvió casi una moda intelectual criticar el desarrollo estabilizador, o sea, el modelo de política económica que tan buenos resultados había rendido a lo largo de su aplicación.

El politólogo Luis Medina Peña ha hecho una reseña bastante pormenorizada de lo que fue esa corriente de análisis crítico. ${ }^{1}$ Según tan autorizada fuente, un intento pionero correspondió a Ifigenia Martínez con los primeros estudios que se realizaron en México sobre distribución del ingreso. Poco tiempo después, el también economista David Ibarra alimentó ese debate con un texto que en su momento cobró mucho prestigio. ${ }^{2}$ A esa tendencia se sumaron posteriormente otros académicos y escritores, entre ellos, Miguel S. Wionczek y el entonces joven economista Francisco Javier

${ }^{1}$ Medina, Hacia, 1994, pp. 169-174.

2 Ibarra, "Mercados", 1970, pp. 89-199. 
Alejo. El primero centró sus críticas en el estrangulamiento de los ingresos fiscales y el segundo en la incapacidad estructural del Estado para incrementar sus fuentes de tributación. Otro actor relevante fue Jorge Eduardo Navarrete con su tesis de que los ingresos por exportaciones serían insuficientes para cubrir los egresos por importaciones que eran inflexibles y crecientes.

No se trata de alegar que como esquema de política económica el llamado desarrollo estabilizador haya sido perfecto, sin defectos e insuficiencias. Tampoco de invocar que los argumentos críticos de los analistas mencionados carecieran de fundamento. El gran problema derivó de que el cambio de política económica que supuestamente se requería en México, y que se produjo en los sexenios de Echeverría y López Portillo, desembocó en uno de los mayores desastres económicos de que se tenga noticia.

¿Qué fue lo que ocurrió en materia de política económica en la transición del desarrollo estabilizador (1958-1970) al denominado desarrollo compartido (1970-1976) y al expansionismo petrolero de José López Portillo (1976-1982)? En su esencia, lo que sucedió fue que un eclecticismo funcional, como fue el modelo del desarrollo estabilizador, resultó reemplazado por otro modelo, también ecléctico, pero con rasgos altamente disfuncionales. El desarrollo estabilizador fue ecléctico en razón de que en su concepción se logró amalgamar un paquete de políticas ortodoxas con otro de políticas heterodoxas. En particular, dicho modelo se diseñó y aplicó para que pudiera lograrse una gran congruencia entre los objetivos de crecer de manera sostenible con elevaciones también permanentes de los salarios reales y la meta de conservar invariable la fijeza del tipo de cambio. ${ }^{3}$ En contraste, la disfuncionalidad de los modelos sucesores aplicados en los sexenios de los presidentes Echeverría y López Portillo -que en su esencia fueron el mismo, según se argumenta en este trabajo-derivó principalmente de la incompatibilidad de utilizar el gasto público como motor del crecimiento y el mantenimiento de la estabilidad cambiaria. Ante la devastación económica, la reacción de la autoridad fue buscar un chivo expiatorio: lo encontró en la banca privada y en los banqueros.

\section{EL PLANTEAMIENTO}

A un cuarto de siglo de que ocurriera, aún no contamos con explicaciones satisfactorias sobre las causas de la expropiación bancaria que decretó el presidente José López Portillo en 1982. Explicación no es lo mismo que

${ }^{3}$ Ortiz, Desarrollo, 1998, pp. 42-43. 
recuento o crónica. Respecto a esto último se sabe lo que pasó. Cuando la crisis económica se hacía más intensa, el presidente López Portillo ordenó la conformación de un grupo de trabajo de cuyas deliberaciones derivaran propuestas para enfrentar la situación anómala en la que había caído la economía. De las reflexiones de ese grupo emanaron dos recomendaciones: primera, aplicar un control integral de cambios para evitar que pudieran ocurrir nuevamente fugas masivas de capital y poder así "independizar a la política financiera interna de la tiranía del mercado internacional de dinero y capitales". ${ }^{4}$ Segunda, expropiar la banca como castigo por la especulación que se había vivido y con el fin de instrumentar una política de crédito verdaderamente popular, congruente con los propósitos de desarrollo de la nación.

La anterior no es propiamente una explicación. Esta, para que sea digna del nombre, tiene que aportar argumentos convincentes sobre las razones que llevaron a la toma de una decisión de poder. Una explicación de ese hecho traumático es lo que se intenta en las páginas que siguen. La secuencia causal de la medida arranca necesariamente de una postura doctrinal en materia de pensamiento económico. Toda propuesta de política económica tiene siempre detrás un enfoque doctrinal. Eso es lo que ocurrió en los sexenios de los presidentes Luis Echeverría y José López Portillo. El esquema de política económica que se derivó de ese cambio doctrinal estaba preñado de al menos una contradicción inexorable: la incompatibilidad entre el expansionismo monetario y fiscal que proponía y el mantenimiento de un tipo de cambio fijo. El desenlace se repitió, prácticamente idéntico, hacia las postrimerías de las presidencias de Echeverría y López Portillo. Puesto que en esta última la crisis estalló a varios meses de la conclusión del periodo presidencial y que la administración lopezportillista tuvo más tiempo que su precedente para preparar una reacción drástica y autoritaria, de ese caldo de cultivo emanó la determinación de expropiar la banca privada.

En términos generales, el mismo esquema de política macroeconómica se aplicó en ambos sexenios. Por supuesto que hubo algunas diferencias, pero estas se mostraron sobre todo en políticas complementarias a la estrategia principal. Así, de la aplicación de un enfoque de política macroeconómica similar se obtuvieron resultados semejantes. Las dos administraciones terminaron en crisis devaluatorias muy graves con sobreendeudamiento. La acumulación de deuda durante el sexenio de López Portillo fue más intensa, porque la palanca del petróleo permitió la obtención de créditos más cuantiosos. Sin embargo, el hecho que cabe destacar es la

${ }^{4}$ Tello, Nacionalización, 1984, p. 126. 
inadvertencia que se adivina en el diseño de la política económica a principios de la administración lopezportillista: ninguna enseñanza se derivó de las lecciones económicas que ofrecían en bandeja los resultados negativos del sexenio precedente. La moraleja fue por tanto inexorable: la misma estrategia arrojó resultados semejantes, y a iguales resultados correspondió una decisión expropiatoria por parte de la autoridad gubernamental: en el caso del sexenio echeverrista, sobre las tierras agrícolas del Valle del Yaqui; en el sexenio lopezportillista, sobre la banca privada.

\section{CORRIENTES DE PENSAMIENTO}

El eclecticismo que caracterizó a la política económica seguida por México de 1970 a 1982 tuvo orígenes diversos. En su esencia, se trató de una combinación más bien espontánea y no planeada de keynesianismo, estructuralismo, proteccionismo, diversas versiones del marxismo y algo de teoría de la dependencia. Con acierto, Joseph Love ha visto que ese arreglo de enfoques fue resultado de un proceso evolutivo más o menos largo. Un proceso de pensamiento, debate y acción en América Latina en el cual siempre estuvo involucrado México con mayor o menor intensidad. ${ }^{5}$ Sorprendentemente, en su libro sobre el pensamiento teórico para el desarrollo económico de los países del tercer mundo, ese autor hace poco énfasis en las recetas del keynesianismo. Sin embargo, al menos para el caso de la política económica de México durante los gobiernos del populismo desarrollista (1970-1982) ese enfoque fue fundamental.

La forma en que esas corrientes de pensamiento tuvieron influencia académica y gubernamental en México queda ejemplificada en el caso de la escuela estructuralista encabezada por Raúl Prebisch. El economista argentino vivió en México durante dos periodos importantes, aunque breves, de su carrera intelectual y tuvo pronunciamientos relevantes en eventos que se celebraron en nuestro país a lo largo de varias décadas. Desde el punto de vista geográfico, los nudos fundamentales para el desarrollo del enfoque fueron las ciudades de Santiago de Chile, Buenos Aires, Río de Janeiro y México. Prebisch concibió varios paradigmas que en su momento tuvieron mucho impacto: la tesis del intercambio desigual, el concepto de los términos de intercambio, las tesis del centro y la periferia, la necesidad del proteccionismo, la industrialización mediante la sustitución de importaciones. ${ }^{6}$ Además de que efectivamente el gobierno

${ }^{5}$ Love, Crafting, 1996, p. 216.

${ }^{6}$ Ibid., pp. 126-132. 
de México puso en ejecución una estrategia de industrialización acorde con ese enfoque y con la Comisión Económica para América Latina de las Naciones Unidas (CEPAL), Prebisch tuvo en el país discípulos distinguidos como David Ibarra, secretario de Hacienda de 1977 a 1982.

La política económica ecléctica que se aplicó de 1970 a 1982 también recibió influencia de las corrientes de pensamiento marxistas. Entre los agentes de esta influencia no sólo actuaron los exponentes de la versión "talmúdica" -la expresión es de Rolando Cordera-, sino de otras expresiones más sofisticadas. Los contactos se establecieron de preferencia con autores europeos, como el francés Althusser o el italiano Gramsci. En el medio mexicano no faltaron seguidores de estos enfoques. Uno de ellos, el propio Rolando Cordera y Horacio Flores de la Peña. Ambos simpatizaban y abogaban por la estatización de los sectores clave de la economía. Desde su tesis de licenciatura, Cordera proclamó la necesidad de expropiar el sector financiero para poderle dar rumbo al proceso de desarrollo.

No por casualidad, los grupos de académicos e intelectuales marxistas fueron uno de los canales por los cuales se difundieron en México las ideas vinculadas con la llamada teoría de la dependencia. Como es posible leer en Packenham, los principales autores que crearon esa corriente, como el brasileño Cardoso o el alemán Gunder Frank, fueron editados y ampliamente leídos en México. Asimismo, los textos de esa corriente tuvieron generosa cabida en los programas académicos de las ciencias sociales. A mayor abundamiento, varios autores mexicanos se adhirieron a esa corriente y apoyaron sus investigaciones en las ideas básicas de la misma; sobresalen en esta categoría Rodolfo Stavenhagen y Pablo González Casanova. ${ }^{7}$ El enfoque tuvo también mucha penetración en los medios intelectuales en los que se volvieron referencia obligada los nombres de Ruy Mauro Marini, Furtado, Osvaldo Sunkel y varios más.

Pero los conceptos de la teoría de la dependencia no sólo se convirtieron en patrimonio e instrumento de trabajo de académicos e intelectuales, también penetraron en la mente y en el discurso de una gama muy amplia de clérigos, luchadores civiles, periodistas, editores, agentes políticos e incluso jefes de Estado. Escribe Packenham que las ideas dependentistas "tanto ortodoxas como heterodoxas adquirieron prominencia en los gobiernos de Luis Echeverría en México (1970-1976), Michael Manley en Jamaica (1972-1980) y Maurice Bishop en Granada (1979-1983)" . ${ }^{8}$ En México, la retórica tercermundista de la que abusó el presidente Echeverría durante su administración estuvo claramente impregnada de esa influencia.

\footnotetext{
${ }^{7}$ Packenham, Dependency, 1992, pp. 31, 191-193.

${ }^{8}$ Ibid., pp. 3, 194.
} 
También, aunque en menor medida, la llamada Carta de los Deberes y Derechos Económicos de los Estados que tanto impulsó ese mandatario.

Al tratarse de una investigación referida en exclusiva a la economía de México, Sarah Babb ha logrado ubicar con mayor precisión los orígenes de las políticas económicas que se aplicaron durante "la respuesta populista de 1970 a 1982 [sic]”. La visión de esa investigadora es clara y convincente:

Durante los años setenta, cuando los recursos externos eran relativamente abundantes y libres de condiciones para el gobierno mexicano y los ingresos del petróleo eran todo el tiempo altos, los economistas educados en el extranjero de la extrema izquierda del consenso desarrollista -los "estructuralistas" mencionados por los politólogos- llegaron a ocupar puestos importantes en la elaboración de las políticas... Entre estos economistas estaban José Andrés de Oteyza y Carlos Tello, quienes habían realizado estudios de posgrado en la Universidad de Cambridge, un conocido centro de pensamiento keynesiano. En general, estos funcionarios creían en la "profundización" del proceso de sustitución de importaciones de México y la aceleración del crecimiento económico mexicano aun a costa de la inflación. ${ }^{9}$

Si a lo anterior se agrega el intento, durante el régimen de Echeverría, de aumentar lo más posible el campo de influencia del sector paraestatal combinado con el compromiso de conservar indefinidamente la estabilidad cambiaria, se tiene una imagen general de lo que fueron las principales políticas económicas en esos dos sexenios.

\section{Los economistas de Luis EcheverRÍa y José LóPEz Portillo}

¿Cómo integró el presidente López Portillo su gabinete económico? En la integración de un gabinete económico ecléctico, e incluso dialéctico, López Portillo estuvo "convencido de que podía conciliar los extremos de las posiciones, no coincidentes, que buscaban el bien del país y que ambas, tenían sus propias razones". ¿Por qué habría deseado ese presidente conformar un gabinete "disímbolo, destinado, desde su origen a la lucha"? Desde un ángulo programático, deseaba disponer "frente a los fenómenos, fundamentalmente los económicos" de "opciones dentro de la gama de posibilidades de nuestro sistema”. En lo personal, aquel mandatario, que apenas iniciaba su encomienda de gobierno, se sentía confiado en

${ }^{9}$ Babb, Proyecto, 2003, pp. 166-167. 
su "juicio para decidir y en [su] capacidad para ejecutar". ${ }^{10}$ Así, en cuestiones económicas, López Portillo se concibió a sí mismo, literalmente, como "el fiel de la balanza" entre los economistas "monetaristas" y los "estructuralistas".

Hacer un deslinde preciso entre las corrientes de pensamiento que existen en la ciencia económica no es tarea fácil. Como se vio, las fronteras son difusas y a ello se suma una complicación: la imprecisión de las denominaciones. Sin embargo, para López Portillo todo se resolvía en una dicotomía tajante entre "estructuralistas" y "monetaristas". Pero más que un esfuerzo de definiciones precisas, lo que se intenta a continuación es una tipología de la que se pueden derivar orientaciones pragmáticas. Así, no resulta aventurado ni inexacto apuntar que los economistas cercanos a Luis Echeverría y a José López Portillo provenían en lo fundamental de tres bandos más o menos bien definidos. En primer lugar cabe citar a los neokeynesianos, por la gran influencia que tuvo en su forma de pensar una cierta exégesis de las ideas del economista inglés, John M. Keynes. En los elencos económicos de ambos sexenios figuraron también los cepalinos, inspirados en las propuestas de la CEPAL. El cuadro se completa con un grupo más amplio, los denominados "reformistas", en el que se ubicaron en forma natural los economistas más radicales de ambos elencos. Para ambos sexenios, cada una de estas categorías puede poblarse con una lista de figuras sobresalientes. No se intenta aquí ese ejercicio, pues la finalidad de estas líneas no es la de hacer acusaciones personalizadas, sino intentar explicar lo que pasó desde un punto de vista histórico.

Quizá el componente con mayor peso en el marco de las políticas económicas de aquellos dos sexenios haya sido de corte keynesiano. El presidente Echeverría señaló con claridad en su discurso de toma de posesión: "la revolución acelerará su marcha" y "de hecho el empleo y el ingreso deben incrementarse con mayor rapidez que hasta ahora". ${ }^{11}$ Por su parte, para el presidente López Portillo la idea económica central fue "promover un crecimiento económico alto" para "lanzar al país a un desarrollo posible". ${ }^{12} \mathrm{Al}$ igual que en el sexenio anterior, en el periodo de López Portillo de nuevo se pensó en el gasto público como motor del crecimiento, el cual estuvo impulsado por el poderoso combustible de los excedentes petroleros. En el Plan Global de Desarrollo 1980-1982 se dijo expresamente

\footnotetext{
${ }^{10}$ López Portillo, Tiempos, 1988, pp. 496-497.

${ }^{11}$ Solís, Economic, 1981, pp. 199-206.

${ }^{12}$ López Portillo, Tiempos, 1988, p. 475.
} 
que entre los instrumentos de política económica destacaba el gasto público "para estimular y dar orientación al crecimiento del país". ${ }^{13}$

El enfoque cepalino se concretó en una vertiente que fue muy importante en la política económica de ambos sexenios: la explicación de las causas de la inflación y las recetas de política para combatirla. Hubo en ambos sexenios el intento deliberado de rechazar y descartar la concepción monetarista para explicar la inflación, la cual es causada en su origen, según ese enfoque, por el exceso de liquidez en la economía:

La política antiinflacionaria debe buscar las causas que generan el proceso inflacionario en los problemas estructurales de la economía y de la sociedad; en el desfase entre una demanda agregada creciente, pública y privada, y una oferta de bienes y servicios que no se desarrolla con la misma velocidad que aquella; en los efectos que en la economía tiene la inflación internacional; en lo oneroso del sistema comercial y en los desajustes coyunturales que se traducen en actividades especulativas. ${ }^{14}$

En la designación "reformistas" se incluye un universo más diversificado de concepciones y posturas, la importancia de todas ellas dentro de la estrategia económica de ambos sexenios no fue despreciable. El catálogo de esos enfoques puede resumirse en tres encabezados principales: estatismo, controlismo y dirigismo. Estatismo en aquellos sexenios significó principalmente la participación del gobierno como propietario y administrador de unidades productivas. Por controlismo cabe entender la voluntad de las autoridades de fijar discrecionalmente los precios de bienes y servicios, y en especial los precios clave: salarios, tasas de interés y tipo de cambio. En el rubro dirigismo se incluyen las políticas regulacionistas del funcionamiento de los mercados, ámbito en el que sobresalió el proteccionismo comercial.

\section{RADIOGRAFÍA DEL MODELO ECONÓMICO}

En términos macroeconómicos el modelo planteado en el Plan Nacional de Desarrollo expedido en 1980 implicaba cinco grandes objetivos: 1) crecimiento económico más rápido que en el desarrollo estabilizador, 2) control de la inflación, 3) tipo de cambio fijo, 4) elevación de los salarios y 5) equilibrio de la balanza de pagos. En términos esquemáticos, el plantea-

\footnotetext{
${ }^{13}$ Secretaría de Programación y Presupuesto, Plan, 1980, pp. 93, 89.

${ }^{14}$ Ibid., p. 132.
} 
miento de esos objetivos y su vinculación con los instrumentos de política económica planteados se muestran en el cuadro 1.

Lo primero que se desprende de la imagen anterior es que el aumento del empleo no está directamente especificado entre los objetivos. La razón es obvia: la elevación de la ocupación sería una consecuencia directa de que se consiguiera la meta principal que era un crecimiento del producto real a $8 \%$ anual. La segunda observación, más de fondo, es que el modelo presenta un desbalance entre objetivos e instrumentos. ${ }^{15}$ La palanca para conseguir el control de la inflación no era en realidad un instrumento sino el objetivo principal del modelo. Asimismo, las revisiones salariales se presentaban como un instrumento débil o poco eficaz para alcanzar la elevación de los salarios reales si no venían acompañadas de otro requisito que ni siquiera fue planteado por los promotores del modelo: la precondición de que la productividad aumentara en forma ininterrumpida. En ese mismo orden de ideas, también la contención de las importaciones parecía un instrumento débil si una expansión de la producción tan rápida forzaba una ampliación excesiva del déficit en la cuenta corriente. Notará también el lector que las políticas fiscal y monetaria no aparecen en la lista de instrumentos. Ello se explica en razón de que ambas quedaron subordinadas al instrumento prioritario de la política económica, que era el gasto público. Por eso mismo, sin ejercerse un control desde la autoridad de las políticas fiscal y monetaria, tanto más dudosa se presentaba la perspectiva de poder asegurar un manejo ordenado de la balanza de pagos con tan sólo dos mecanismos: la contención de las importaciones y el financiamiento del déficit en la cuenta corriente mediante el recurso del crédito exterior.

Dicho modelo presentaba dos tendencias hacia el desequilibrio que hacían discutible que su aplicación resultara en un crecimiento sostenido del producto. La primera de esas tendencias era hacia la generación de una inflación superior a la del exterior y, por tanto, hacia una sobrevaluación creciente del tipo de cambio. La segunda, hacia la gestación de déficit en la balanza de pagos que quizá llevara a saturar la capacidad del país para endeudarse con el exterior. Ambas tendencias eran tanto más probables cuanto que las políticas fiscal y monetaria se verían sometidas a presiones expansionistas muy poderosas, en la medida en que estaban subordinadas y se verían arrastradas por un gasto público en rápida expansión.

Es posible así visualizar en la aplicación de la estrategia de desarrollo descrita dos etapas evolutivas. Una primera en la que los indicios de inflación serían incipientes y en la que la apreciación gradual del tipo de cambio sería escasamente percibida por la mayoría de los agentes económicos.

${ }^{15}$ Tinbergen, Economic, 1956, pp. 11-24. 


\section{CUADRO 1. MODELO ECONÓMICO 1980-1982. \\ OBJETIVOS E INSTRUMENTOS DE LA POLÍTICA ECONÓMICA}

\section{Instrumento}

Gasto público

Crecimiento 8\%

Contención de las importaciones

Revisiones salariales

Crédito externo

\section{Objetivo}

Crecimiento $8 \%$

No inflación

Conservación del tipo de cambio fijo

Elevación de salarios

Equilibrio de balanza de pagos

Fuente: Elaboración propia con base en Secretaría de Programación y Presupuesto, Plan, 1980, pp. 93, 89.

Si se mantenía la fijeza del tipo de cambio, no pasaría mucho tiempo antes de que la sobrevaluación de la paridad se hiciera evidente para sectores amplios de la población. Los viajeros que salieran al exterior regresarían al país platicando que el extranjero "está muy barato". Así, la segunda etapa de aplicación del modelo estaría marcada por las fugas de capital que indujesen a la sobrevaluación del tipo de cambio. Y de ello se derivaría una doble necesidad para contratar crédito externo: la de financiar el déficit en cuenta corriente y la de reponer las pérdidas que sufriría la reserva internacional del banco central.

A los proponentes del modelo de desarrollo que eligieron primero el presidente Echeverría y luego su sucesor López Portillo los animó la sana intención de generar un crecimiento más rápido. Se les olvidó, sin embargo, el importantísimo detalle de la sostenibilidad de ese crecimiento. Implícitamente, su modelo contenía el germen de esa secuencia de "siga y pare" a la que tanto propalaba temer el presidente López Portillo. Desde su concepción el modelo estaba inoculado de proclividad a la crisis, pues su mecánica era incapaz de resolver dos incógnitas fundamentales: cómo combatir con eficacia la inflación y cómo impulsar las exportaciones para evitar la crisis de la balanza de pagos. Así pues, hubo en ese enfoque analítico dos omisiones de suma gravedad: la primera respecto a la interconexión que existe entre el déficit fiscal y la inflación; la segunda, en relación con el nexo insalvable entre la liquidez en la economía y el déficit en la cuenta corriente de la balanza de pagos.

Sólo por razones de balance macroeconómico, un déficit fiscal ejerce una influencia muy poderosa sobre el sector externo, absorbiendo parte del excedente exportable e induciendo un crecimiento muy agresivo de 
las importaciones. ${ }^{16} \mathrm{El}$ caso del llamado enfoque monetario de la balanza de pagos es igualmente interesante y sugestivo. Considerando constante todo lo demás (ceteris paribus), la ampliación de la oferta monetaria redundaría en la generación de déficit en la balanza de pagos y, por lo tanto, en pérdida de divisas por parte del banco central que las suministró para financiar ese déficit. ${ }^{17}$

\section{CRÓNICA DE UN DESENLACE ANUNCIADO}

Con gran orgullo proclamó el presidente José López Portillo que su sexenio sería el de la planificación económica. El Plan Nacional Industrial se dio a conocer a principios de 1979 y el Plan Global de Desarrollo vio la luz pública en abril de 1980. En el primero de ellos, la predicción del crecimiento del PIB real para 1982 fue de $10.6 \%,{ }^{18}$ mientras que en el plan global el crecimiento promedio del PIB real para los últimos tres años del

${ }^{16}$ Una muy importante identidad de la macroeconomía abierta señala que: $C C=(S-I)+(T-G)$, en donde $\mathrm{CC}$ es cuenta corriente; $\mathrm{S}$, ahorro privado; I, inversión privada; $\mathrm{G}$, gasto público y T, ingresos fiscales. Así, todo lo demás constante, el déficit en CC aumentará en la medida en que se amplíe la brecha entre T y G.

${ }^{17} \mathrm{El}$ planteamiento formal del paradigma es bastante más complicado, mas no incompatible con la deducción expuesta en el texto. En este planteamiento simplemente se añade a la secuencia descrita la remoción del supuesto ceteris paribus. El planteamiento es como sigue:

$$
\frac{\dot{R}}{R}=\frac{M_{1}}{R}\left[\frac{\dot{P}}{P}+\varepsilon_{y} \frac{\dot{Y}}{Y}+\varepsilon_{r} \frac{\dot{r}}{r}+\varepsilon_{I} \frac{\dot{I}}{I}-\frac{\dot{m}}{m}\right]-\frac{D}{R} \frac{\dot{D}}{D}
$$

En donde $\mathrm{R}$ son las reservas internacionales del banco central; $\mathrm{P}$, el nivel de los precios; $\mathrm{Y}$, el nivel del producto nacional; r, la tasa de interés; I, la inflación; m, el multiplicador monetario, resultante de dividir oferta monetaria entre el monto de M1 (base monetaria más depósitos a la vista), y H, la base monetaria. Por su parte, ey, er y eI son las elasticidades de la demanda de dinero respecto al producto, a la tasa de interés y la inflación; y

$$
\begin{aligned}
& \frac{\dot{P}}{P}, \frac{\dot{m}}{m} \text { y } \frac{\dot{D}}{D} \text { las tasas de crecimient } \\
& \text { etario y del crédito interno del banco } \\
& \text { aso general da lugar a que el primer } \\
& \text { stante, es decir, } \\
& \frac{H}{R}\left[\frac{\dot{P}}{P}+\varepsilon_{y} \frac{\dot{Y}}{Y}+\varepsilon_{r} \frac{\dot{r}}{r}+\varepsilon_{I} \frac{I}{I}-\frac{\dot{m}}{m}\right]=C
\end{aligned}
$$

Entonces es posible escribir la fórmula general como sigue: $\frac{\dot{R}}{R}=C-\frac{D}{R} \frac{\dot{D}}{D}$. De donde se desprenden dos conclusiones de la máxima importancia: $a$ ) la primera y más relevante, que mientras más rápida sea la tasa de crecimiento del crédito interno, más rápido será también el ritmo de declinación de las reservas internacionales del banco central; b) la fuerza de ese impacto causal será tanto más intensa en la medida en que el saldo del crédito interno del banco central sea mayor que el saldo de la reserva internacional. Fuente: Rubli, "Marco", 1992, pp. 298-300.

${ }^{18}$ Secretaría de Patrimonio y Fomento Industrial, Plan, 1979, p. 9. 
sexenio se estimó en $8 \%$ anual. ${ }^{19}$ Pero en el sexenio que iba a ser el de la planificación, los planes fracasaron de manera estrepitosa. Mientras que en los hechos -y con la economía ya probablemente sobrecalentada- el crecimiento del PIB real llegó hasta 9.2\% en 1979 y quedó por arriba de 8\% en los dos años siguientes, en 1982 la economía se desplomó hasta experimentar contracción. Los planificadores fracasaron en generar un crecimiento sostenible.

En la secuencia de causalidades que desembocaron en el desplome, el elemento primigenio de los problemas fue el gasto público. De acuerdo con el Plan Global de Desarrollo, este agregado debería crecer, en la segunda parte del sexenio, a 14\% anual. ${ }^{20}$ Una expansión tan acelerada de ese agregado dio lugar en el segundo círculo concéntrico de causalidades a un déficit fiscal creciente. A continuación, el déficit fiscal en ampliación continua tuvo dos consecuencias principales: en el frente interno, una ampliación muy rápida de la liquidez en la economía provocó una inflación también creciente, a pesar de que hasta principios de 1982 el tipo de cambio fijo actuó como ancla en el sistema de precios; en el frente externo, el déficit en la cuenta corriente de la balanza de pagos que había que financiar.

Los problemas que se suscitaron en la balanza de pagos se iniciaron con un crecimiento incontrolado de las importaciones. Estas tuvieron como motor el expansionismo fiscal y monetario característico de la época. Crecían sin freno las importaciones y con ellas el déficit en la cuenta corriente. El otro factor desequilibrante fue el de las fugas de capital. Con un tipo de cambio nominal fijo y un tipo de cambio real en depreciación continua, pronto el peso mexicano entró en una espiral muy visible de sobrevaluación. En ese contexto, el endeudamiento externo que se produjo en el periodo respondió a dos motivos: el primero, y a lo largo de todo el sexenio, a la necesidad de financiar el déficit en la cuenta corriente. El segundo, cuya fuerza se intensificó a medida que pasó el tiempo y se hizo más marcada la sobrevaluación, a la necesidad de financiar las fugas de capital, pues el presidente se negaba a modificar el tipo de cambio nominal. "Presidente que devalúa, se devalúa", declaró alguna vez López Portillo.

Deliberadamente, esta sección que tiene como tema los resultados económicos en el sexenio de José López Portillo se conformó con datos y cifras que en muy buena medida hablan por sí mismos. Lo importante es presentar esas estadísticas en el sentido secuencial de los acontecimientos. En los años de gran expansión del sexenio de López Portillo -de 1977 a

\footnotetext{
${ }^{19}$ Secretaría de Programación y Presupuesto, Plan, 1980, pp. 81-83.

${ }^{20}$ Ibid., pp. 88-90.
} 
1981-, el gasto público pasó, en términos reales (a precios de 1980), de 605300000 a 1078 millones 200000 pesos, con una tasa de crecimiento anual en ese periodo de casi $12 \%$. Como proporción del PIB, ese indicador avanzó de $17.7 \%$ en 1977, a 22.2\% en 1981, para cerrar el sexenio en $20.3 \%$. Como consecuencia, el déficit fiscal también medido como proporción del PIB se incrementó de 4.9\% en 1977, a 12.3\% en 1981, para llegar hasta $14.7 \%$ en 1982. Por su parte, la deuda externa pública, según datos de la balanza de pagos, se incrementó en el sexenio de 20300 a 60300 millones de dólares. En lo que hace a los indicadores monetarios, de 1977 a 1981 el saldo de billetes y monedas en poder del público pasó, en términos reales, de 130300 a 178400 billones de pesos. El inmenso potencial inflacionario de esa expansión monetaria desembocó inexorablemente en inflación. Así, en el sexenio lopezportillista la inflación anual pasó de 16.2\% en 1978, a 29\% en 1981, para llegar hasta casi $100 \%$ en $1982 .^{21}$

El otro aspecto que cabe señalar es el paralelismo evolutivo de la economía en los sexenios de Echeverría y López Portillo. Ese paralelismo no debe sorprender después de todo lo hasta aquí dicho: la misma estrategia económica desembocó en consecuencias parecidas. Cuantitativamente, ya se ha dicho, la diferencia entre ambos sexenios provino de la palanca del petróleo. En el sexenio de López Portillo la opción petrolera dio lugar a que el endeudamiento externo fuera mucho más grande, al igual que la inflación, las devaluaciones y la quiebra en general. En ambos sexenios la crisis económica aguda detonó en el sector externo. El déficit de la balanza de pagos pudo sostenerse mientras se dispuso de crédito externo, de ahí que no deba sorprender el crecimiento continuo de la deuda pública en ambos sexenios y en particular del tipo de cambio real, que de 1970 a 1975 se apreció en casi 20\% y de 1977 a 1981 llegó hasta 37.8\%. Consecuentemente, medido como proporción del PIB, el déficit de la cuenta corriente pasó de 3.7 a 5.1\%, de 1970 a 1975, y de 2.5 a 6.5\%, de 1977 a 1981 . Por su parte, la inflación anual subió de 4.7 a $27.2 \%$, de 1970 a 1976, y de 20.2 a $98.8 \%$ en los años del sexenio siguiente. ${ }^{22}$ Así, a manera de conclusión puede decirse que, como jettatura, en esas dos administraciones la capacidad crediticia del país se agotó hacia el final y la consecuencia inexorable fue la devaluación cambiaria.

\footnotetext{
${ }^{21}$ Mancera, Inconveniencia, 1982.
}

${ }^{22}$ Ibid. 


\section{iLA BARATA DEL SEXENIO!}

La contradicción más flagrante en el proyecto económico del presidente López Portillo residió, ya se ha dicho, en comprometerse a mantener la estabilidad cambiaria en paralelo con la aplicación de expansionismo fiscal y monetario. En esto, como en muchos otros asuntos, el paralelismo con el régimen de Echeverría fue muy cercano. Había que crecer rápido para alcanzar las aspiraciones del proyecto y el gasto público aparecía como la herramienta idónea. Ya en marcha, el enfoque mostró tener un sesgo inflacionario muy marcado. "La inflación no cede", comentó con resignación el presidente López Portillo a principios de 1982, para aportar a continuación la explicación salvadora y autocomplaciente: "pero ya no estamos como estuvimos... con inflación y con recesión". ${ }^{23}$

Lo cierto es que la inflación no cedió nunca a lo largo de ese sexenio, sobre todo después de que, con apoyo en la opción petrolera, México repudió la tutela del Fondo Monetario Internacional y tiró por la borda el plan de crecimiento moderado en tres bienes propuesto por López Portillo a principios del sexenio. Al presidente le despertó sorpresa el fenómeno alcista y quizá también a sus principales asesores económicos, pero las políticas económicas con sesgo inflacionario provocan inflación. Así, aunque el tipo de cambio se mantuviera fijo, la inflación en México divergió visiblemente de la de Estados Unidos.

En términos técnicos, la fijeza del tipo de cambio y la inflación dieron lugar a una apreciación muy marcada del tipo de cambio real. Hacia 19791980 , pero en especial durante 1981, los viajeros mexicanos que visitaban el extranjero notaban como evidente el "encarecimiento" de México y el "abaratamiento" paralelo de lugares tradicionalmente caros como París o Nueva York. Todos los índices de tipo de cambio real indicaban una apreciación muy marcada de la moneda mexicana. La brecha que se fue abriendo entre el tipo de cambio nominal del peso mexicano y el índice de precios interno se ilustra con mucha claridad en la gráfica 1. El argumento es muy contundente: mientras que del principio de ese sexenio a diciembre de 1981 el índice general de precios se incrementó en $280 \%$ (18.6\% anual promedio), el precio del dólar (tipo de cambio) apenas se modificó. ${ }^{24}$ Esos son los números de la gran barata que lanzó la política económica en ese sexenio.

Sin embargo, no hubo reacción por parte de las autoridades ante la gravedad de la sobrevaluación hasta que la situación empezó a entrar en

\footnotetext{
${ }^{23}$ López Portillo, Tiempos, 1988, p. 1167.

${ }^{24}$ Mancera, Inconveniencia, 1982.
} 
GRÁFICA 1. TIPO DE CAMBIO E INPC, 1977-1982

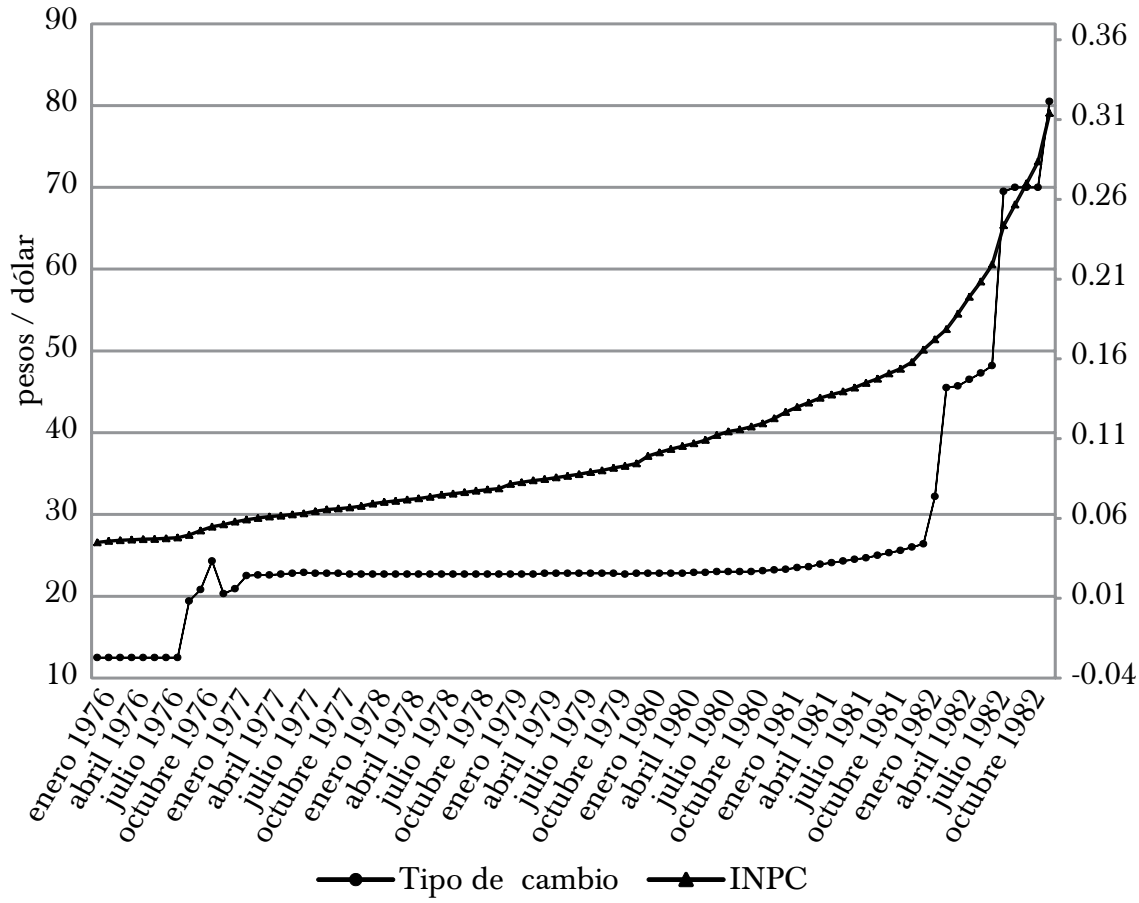

Fuente: Banco de México en <http://www.banxico.org.mx/estadisticas/index.html> [consulta: 10 de octubre de 2010].

verdadera crisis; es decir, hasta que empezó a haber evidencias muy palpables de fugas de capital. ¿Por qué no hubo reacciones en ese sentido? Una explicación es que se pensó que la opción del petróleo todo lo podría compensar, incluso el sostenimiento de un tipo de cambio claramente sobrevaluado. Otra posibilidad es que, ya envuelto en el frenesí petrolero, el presidente López Portillo desdeñó la opinión de los funcionarios considerados peyorativamente como ortodoxos del sector financiero, que se acercaron a informarle sobre la delicadeza y la vulnerabilidad cambiaria que presentaba México. Una razón más es que ese mandatario quizá suponía que podría sostener la paridad con tan sólo un discurso, mediante las vastas reservas de retórica nacionalista y solidaria que había acumulado en su persona. ${ }^{25}$

${ }^{25}$ López Portillo, Tiempos, 1988, p. 1168. 
Los seres humanos que pueblan una nación no son como los que quisiera o ha imaginado el gobernante soñador, así los debe ver y entender el verdadero estadista. López Portillo debió conocer la manera típica de reaccionar de las masas frente a la posibilidad de que hubiese un ajuste cambiario y además desde una posición privilegiada: el mando en la Secretaría de Hacienda. No había por qué desgarrarse las vestiduras con falsos pudores. Los empresarios tratan de conseguir en sus negocios la maximización de las ganancias; los consumidores obtener la mejor oferta y los ahorradores optimizar la protección del patrimonio ahorrado. Si estos últimos perciben el riesgo de que el tipo de cambio se vaya a devaluar, buscarán pasar sus ahorros a una divisa segura. La actitud puede parecer mezquina, egoísta, rastrera, pero no es falsa.

Al igual que las corridas bancarias, los ataques especulativos masivos contra las monedas son fenómenos que se gestan en forma larvada. Y cuando la masa crítica ha desarrollado suficiente volumen, al menor y más imprevisto signo se desata la estampida. Este hecho de vigencia universal debió haber sido informado al presidente López Portillo por sus asesores económicos. Si no ocurrió así, la omisión fue su responsabilidad y supletoriamente la de ellos. O como apuntó Enrique Pérez López: “quien tiene todo el poder, tiene toda la responsabilidad". ${ }^{26}$

Hacia el penúltimo año del sexenio lopezportillista, el dólar ya estaba muy barato. La primera señal para que se destapara la cargada contra la moneda nacional -la "sacadera de dólares", según el lenguaje de López Portillo- llegó cuando bajó el precio internacional del petróleo, hacia junio de 1981. Pero, meses más tarde, el propio presidente les dio otro banderazo de salida a los especuladores cuando, seguramente con la mejor de las intenciones, informó a la nación a voz en cuello: "estamos dándole ritmo al valor de nuestra moneda con el desliz, con los aranceles, con las licencias y con los estímulos y fomento a las exportaciones. Esa es la estructura que le conviene al país..., la que me he comprometido a defender como perro." ${ }^{27}$ Estas frases se pronunciaban a principios de febrero de 1982. La primera devaluación se anunciaba pocos días después, el 17 de ese mes. Posteriormente, vendrían muchas otras que llevaron el tipo de cambio a cotizaciones incluso superiores a 100 pesos por dólar.

\footnotetext{
${ }^{26}$ Pérez, Expropiación, 1987, p. 89.

${ }^{27}$ López Portillo, Tiempos, 1988, p. 1168.
} 


\section{EXPLICACIÓN PARA LAS FUGAS DE CAPITAL}

La posteridad puede conocer la forma de pensar de los asesores económicos más radicales del presidente López Portillo por los testimonios de una de sus principales figuras: Carlos Tello. "Desde luego que la situación financiera del país a fines de 1981 y a principios de 1982 era delicada y de difícil manejo", reconoció Tello en su libro sobre la nacionalización bancaria. Sin embargo, añadió a continuación, "la resistencia a utilizar instrumentos de política económica idóneos, aunque desde luego no ortodoxos, para enfrentar situaciones difíciles y prácticas especulativas [...] explica, en buena medida, la crítica situación por la que atravesaron la moneda, las finanzas -públicas y privadas- y la economía mexicana en 1982".

Esta última aseveración es en extremo polémica. No es claro que la gravedad de la circunstancia económica en ese trance se debiera exclusivamente a la renuencia a utilizar instrumentos de política "no ortodoxos" y, además, otro interrogante clave: ¿cuáles eran esos instrumentos? Al parecer sólo tres: estatizar la banca, instaurar un control generalizado de cambios y medidas tendentes a restringir las importaciones. ${ }^{28}$

Según Tello, la cuenta corriente es un rubro que puede "pronosticarse con relativa certeza". A pesar de todos los problemas y dificultades que se vivieron desde 1981 y a lo largo de 1982, el financiamiento de ese déficit "no presentaba problemas insalvables". En contraste, "las fugas especulativas de capital son totalmente impredecibles y su magnitud potencial era inmensa". Aparte de errores de instrumentación, de que se habían hecho previsiones demasiado optimistas sobre la evolución futura del precio internacional del petróleo y de la necesidad de "hacer un alto en el camino para encauzar por una vía más sólida -aunque menos acelerada- la expansión de la economía en razón de que el gasto había ido muy por encima de lo planeado", el factor desestabilizante último fueron, en su opinión, las fugas de capital. ${ }^{29}$

A juicio de Tello, tres fueron los factores causales de "la salvaje especulación y fuga de capitales" que se materializó hacia el último bienio de la presidencia de José López Portillo. El primero había sido "la política de irrestricta libertad cambiaria" que permitía que tuviese lugar "la especulación contra el peso". Por supuesto, el segundo, y elemento acelerador, había sido la presencia de la banca privada, "altamente especulativa", la cual había instrumentado e incluso aconsejado y auspiciado la fuga de capitales. El tercero, que cerró la pinza cancelando supuestamente toda po-

${ }^{28}$ Tello, Nacionalización, 1984, pp. 110-111.

${ }^{29}$ Ibid., pp. 121, 113, 115. 
sibilidad de solución, fue "la falta de acción de las autoridades" para impedir las prácticas especulativas mediante la utilización de "instrumentos de política económica idóneos aunque desde luego no ortodoxos". En otras palabras, la renuencia a "no variar la política de la libre convertibilidad de la moneda" mediante la implantación de un control integral de cambios..$^{30}$

Nótese que la enumeración en el párrafo anterior no contiene la mención de una sola causa de la fuga de capitales. La irrestricta libertad cambiaria era sólo una posibilidad pasiva para que la especulación lograra sus propósitos. La banca privada había actuado tan sólo como instrumento y coadyuvante de las conductas especulativas, no como causa activa de estas. Por último y de mayor importancia, la eventual aplicación del control de cambios (instrumento de muy dudosa efectividad) sólo impediría las fugas de capital, pero no suprimiría sus causas. Curioso y sorprendente que Tello admitiera que existía "sobrevaluación del peso" y, además, que con el paso de los meses se hubiera agudizado "gradualmente la desconfianza [del público] sobre el tipo de cambio", pero que no asociara causalmente esos fenómenos con la especulación y con la fuga de capitales. Si la situación prevaleciente en 1981 y 1982 había exacerbado "la ambición desmedida de los especuladores", por la diferencia que se dio, de manera ininterrumpida desde 1977, entre "la tasa de inflación estadunidense y la mexicana" y que, conjugada con el esquema de tipo de cambio fijo, había desembocado en una muy marcada "sobrevaluación del peso frente al dólar", ${ }^{31}$ esa y no otra había sido la causa principal para las fugas de capital.

Ese enfoque explicativo adolecía evidentemente de sentido común y de insuficiente memoria histórica. Durante el llamado desarrollo estabilizador, desde 1955 hasta 1970, existió en México libertad cambiaria irrestricta, banca privada, el mismo régimen político, y no hubo fiebres especulativas contra el tipo de cambio. O en esa época no hubo en el país especuladores inoculados de una "ambición excesiva" o fueron otros los factores que estimularon que aflorara en esa época la especulación cambiaria en volúmenes tan cuantiosos. Notable que Carlos Tello nunca se hiciera esta deducción elemental. A mayor abundamiento: en el mencionado periodo la estabilidad cambiaria y la ausencia de fugas de capital no se habían conseguido como resultado de arrojar a la economía en una recesión mediante el odiado expediente de una política económica contraccionista. De 1955 a 1970 la economía creció en términos reales a un ritmo sostenido por arriba de $6 \%$ anual.

${ }^{30}$ Ibid., pp. 76, 88, 116, 121, 110, 115.
${ }^{31}$ Ibid., pp. $110-111$. 
Obviamente, las causas de que se hubiera suscitado una especulación cambiaria voraz de 1973 a 1976 y luego en 1981 y 1982 residían en razones diferentes a que existiesen en México una libertad cambiaria irrestricta y una banca privada. Que de 1977 a 1982 la inflación en el país fuera significativamente más elevada que en Estados Unidos sólo puede tener una explicación: que la estrategia antiinflacionaria aplicada en ese periodo en México -si la hubo- fue fallida. En realidad, ya se ha visto, no se aplicó durante ese episodio política alguna contra la inflación, sino todo lo contrario. El propio Tello reconoce en su libro que las "presiones inflacionarias por las que atravesó la economía a finales de 1981 y principios de 1982" fueron atribuibles a "ciertos gastos improductivos del sector público" y a "la forma de financiar su déficit". ¿Y cuál habría sido la forma de financiar ese déficit?, parcialmente, pero en medida muy importante, mediante el crédito primario del banco central. El propio Tello llega a una explicación ortodoxa o monetarista de la inflación.

\section{SE TOMA LA DECISIÓN: EXPROPIAR LA BANCA}

La tesis parece apropiada: si a principios de 1982 no hubiera habido devaluación, cierre del crédito externo y problemas cambiarios posteriores, tampoco habría habido expropiación bancaria siete meses después. En una de las cimas del presidencialismo mexicano, una vez más sólo lo presidencial fue relevante: extrapolemos 1980, cuando el presidente López Portillo se ubicó en el cénit de su gloria, a los años restantes del sexenio. ¿Proponer una reforma estructural tan polémica que sacara de cauce la unidad nacional que tanto trabajo había costado restaurar?, ¿dar un golpe de timón que no beneficiaría a ningún grupo de interés y que quizá lesionaría irremediablemente la relación del presidente con uno de los segmentos suscriptores de la Alianza para la Producción? No había razón coyuntural para una medida de esa naturaleza, ni tampoco un antecedente programático o ideológico.

De haber tenido en mente una propuesta reformista, la hubiese tratado de llevar a cabo durante los primeros años de su sexenio. Así lo había hecho el general Cárdenas. Había aprovechado el alba y el mediodía de su periodo presidencial para aplicar la reivindicación justiciera del fraccionamiento de los latifundios e intentar una corrección del reparto del producto entre capital y trabajo. De esta última estrategia había derivado la confrontación laboral que terminó en la expropiación de las compañías petroleras. Los años finales del sexenio cardenista se dedicaron a la consolidación de esos avances, a lograr algo en materia de reconciliación 
nacional y a limar asperezas externas, sobre todo con Estados Unidos. Algo parecido debió ser recomendable hacia finales de su administración para el presidente López Portillo. No era el único presidente que había tenido que devaluar en la era del partido hegemónico. Lo habían hecho antes Lázaro Cárdenas (1938), Miguel Alemán (1948-1949) y Adolfo Ruiz Cortines (1954) y, sin embargo, habían salido relativamente bien librados de su encomienda presidencial.

Esos eran los antecedentes. Sin embargo, el presidente López Portillo había quedado tremendamente dolido con la devaluación. Había expresado públicamente, que "presidente que devalúa, se devalúa". Resulta entonces extraña esta contradicción visible entre su temor a devaluar y la luz verde que dio a una política económica que, con su excesivo activismo fiscal y monetario, estaba condenada a provocar dificultades en la balanza de pagos y, por lo tanto, a abrir la puerta al peligro de devaluación. Parcialmente, la devaluación había sido inducida hacia mediados de 1981 por una reversión desfavorable de los términos de intercambio en México. Pero ese último hecho, no había servido como atenuante para el agravio que el desenlace devaluatorio había infligido al presidente, años después todavía llegó a confesiones reveladoras sobre su estado de ánimo: "los banqueros se resisten a decirme quiénes fueron los que más dólares compraron y para qué. No podemos seguir a la conveniencia de ese jaez de especuladores." 32

Un momento particularmente álgido de la crisis sobrevino el 20 de agosto de 1982. El secretario de Hacienda, Jesús Silva Herzog (sucesor de David Ibarra), negociaba con los banqueros acreedores de México una moratoria temporal por pagos de 90 días. Los contactos con las autoridades financieras de Estados Unidos para venderles petróleo con pago anticipado no habían marchado bien, lo que empeoró aún más la situación. Después de una clausura de algunos días, el mercado de cambios reabrió el 19 de agosto, episodio en el que el tipo de cambio libre llegó a un promedio de 115 pesos por dólar. Durante esos últimos días de agosto de 1982 se intensificaron las fugas de capital, acelerándose en paralelo el deterioro de las reservas internacionales del Banco de México.

La coyuntura debió ser tremendamente difícil. El presidente López Portillo parecía no tener salidas, pero para una fracción importante de sus colaboradores económicos sí había una y a su juicio totalmente justificada. Recurriendo a ella el presidente no sólo podría concluir su sexenio fortalecido, sino además obtener prestigio y hasta celebridad. La solución

\footnotetext{
${ }^{32}$ López Portillo, Tiempos, 1988, p. 1180.
} 
consistía en decretar un control de cambios general y la nacionalización de la banca privada.

¿Cuál fue la mecánica de trabajo de esa tarea? ¿Dónde la realizaron? Aquel grupo trabajó con una cohesión y una discreción excepcionales. Teniendo como sede las oficinas de la Financiera Nacional Azucarera, en el seno de ese equipo se prepararon los proyectos y los decretos para que el presidente pudiera anunciar el control general de cambios y la nacionalización de la banca. La convicción de esos proyectistas respecto a la conveniencia de las medidas que recomendaban era inconmovible. No sólo creían en ellas firmemente, también le profesaban una fe absoluta a la estrategia de desarrollo que le habían sugerido al presidente López Portillo durante su campaña política. Este, como ya se ha dicho, se las había "comprado" sin remilgos y prácticamente sin hacerles ningún regateo. Un sexenio venturoso de tres meses se iniciaría el 1 de septiembre de 1982.

La banca era un sector al que tenían en la mira, desde tiempo atrás, los economistas radicales que estaban cerca de López Portillo. Para un sistema en el cual un grupo de planificadores debía decidir cómo se asignaban los recursos prestables, la existencia de una banca privada presentaba un obstáculo insuperable. Esa circunstancia era una expresión de la incompatibilidad irreconciliable entre la planificación central y el mercado funcionando como el mecanismo guía para decidir la asignación de los recursos prestables. Dicho enfoque desdeñaba la importancia del mercado como brújula para determinar el rumbo de la inversión y creía de preferencia en las bondades del dirigismo para orientar la marcha de la actividad económica. Teniendo en mente esa perspectiva, cualquier coyuntura que diera oportunidad para llevar a cabo una transformación estructural por virtud de la cual la banca pasara a manos del Estado era más que bienvenida. ${ }^{33}$

El caso intelectual del presidente López Portillo era muy diferente, el presidente pudo quedar convencido de que era indispensable estatizar la banca, pero esa acción no era algo que hubiera formado parte de sus convicciones. En un episodio de crisis muy grave, la voluntad de aquellos economistas estatistas logró confluir con la de su jefe, cuando a fines de su sexenio se sintió acorralado. Expropiar la banca le daría la salida de la trampa o, por lo menos, una vía para hacer saber a la opinión pública que, entre los varios culpables de las fugas de capital, no todos habían salido impunes. Hacia el final del sexenio el gobierno se había enfrascado en una confrontación abierta con los empresarios y otros grupos de poder, confrontación que el gobierno no podía perder. Para no salir derrotado en esa

${ }^{33}$ Tello, Política, 1978, pp. 199-203, 207-208. 
encrucijada, el titular del poder ejecutivo recurría a sus facultades legales y exropiaba la banca. ${ }^{34}$

\section{CONCLUSiOnes}

La expropiación bancaria que decidió el presidente José López Portillo hacia las postrimerías de su sexenio tuvo una causalidad que se originó en los siguientes factores: en la estrategia económica que se adoptó, en la corriente de pensamiento subyacente en esa estrategia, en los asesores que profesaban un pensamiento económico afín a medidas expropiatorias en los resultados que fatalmente se obtuvieron y en la reacción del gobierno que necesariamente tuvo que contraatacar dados los rasgos de personalidad del presidente en turno y sobre todo los consejos que le sugerían los asesores económicos con quienes se había identificado su hijo, José Ramón López Portillo.

Con ese trasfondo, de las reflexiones preinsertas se pueden derivar varias conclusiones:

a) El gobierno de José López Portillo aplicó la misma estrategia económica que la administración precedente de Luis Echeverría, a sabiendas de los resultados catastróficos que se habían producido: devaluación, inflación galopante, sobreendeudamiento, crisis de la balanza de pagos, estancamiento de la actividad económica, etcétera.

b) Los encargados de diseñar y aplicar la política económica en los sexenios de Echeverría y López Portillo dejaron puniblemente de tomar en cuenta los incentivos de los agentes económicos. Sobre todo respecto a la cuestión de las fugas de capital, los incentivos eran exactamente en el sentido contrario de lo que deseaban las autoridades.

c) La intensa especulación que se generó a partir de principios de 1981 no fue impulsada, ni mucho menos causada, por la banca privada.

d) Tal vez a los principales economistas de la administración de López Portillo -y con ellos al propio presidente- los encegueció el hecho de contar con la opción del petróleo en un entorno de crecimiento continuo de los precios de los hidrocarburos: "a nosotros no nos va a ocurrir lo mismo".

e) Un gobierno puede hacer concertaciones con el sector privado para alcanzar una variedad de fines, pero no para negociar el mantenimiento de una paridad cambiaria. En el caso de la administración de López Portillo la Alianza para la Producción tuvo éxito para ese fin.

\footnotetext{
${ }^{34}$ López Portillo, Tiempos, 1988, pp. 1208, 1210, 1223, 1248.
} 
f) La crisis económica que estalló hacia finales del sexenio del presidente López Portillo fue causada por la aplicación de una política económica semejante a la que se instrumentó durante el sexenio de Luis Echeverría.

g) Aunque los factores causales de esa crisis derivaron de la política económica aplicada, a su estallido contribuyó también el deterioro que sufrieron los términos de intercambio en México desde principios de 1981 y la elevación de las tasas de interés internacionales.

h) Es completamente contradictoria la instrumentación de una política económica de corte expansionista con el mantenimiento de un tipo de cambio fijo o semifijo. Esta lección vale tanto para lo que sucedió en el sexenio de Luis Echeverría como en el de José López Portillo.

Muchas cosas han cambiado en el mundo y en México desde que el presidente López Portillo decretó la expropiación de la banca privada. En el orden mundial cayó la cortina de hierro y se consumó el fracaso de la economía centralizada. En México, el país avanzó finalmente a la era de la democracia política. Sin embargo, las corrientes de pensamiento que impulsaron a López Portillo a tomar esa medida parecen insensibles a todos esos cambios trascendentales. Su sordera se manifiesta en especial ante dos estímulos que deberían haber sido importantes: las lecciones de la experiencia y el impacto de los críticos que han pretendido polemizar con ellos. En América Latina muchos programas electorales proponen recetas semejantes a las que se aplicaron en México hace tres décadas. Es preocupante que entre el gremio de los economistas mexicanos no esté funcionando el debate que podría llevarnos a una nueva síntesis en materia de política económica. Así, en el ámbito de las corrientes de pensamiento económico poco se ha avanzado en todos los órdenes desde que López Portillo gobernó México. Ojalá que el presente trabajo aporte un grano de arena para movilizar el debate serio y responsable que tanto se necesita en México y América Latina.

\section{BIBLIOGRAFÍA}

Aguilar Camín, Héctor et al., Cuando los banqueros se van, México, Océano, 1982. Aguilar M., Alonso et al., La nacionalización de la banca: la crisis y los monopolios, México, Nuestro Tiempo, 1985.

Ángel, Gustavo del, Carlos Bazdresch y Francisco Suárez Dávila (comps.), Cuando el Estado se hizo banquero, México, FCE, 2005 (Lecturas de El Trimestre Económico, 96). 
Arriola Woog, Carlos, Los empresarios y el Estado 1970-1982, México, unAm/Miguel Ángel Porrúa, 1988.

BABb, SARAH, Proyecto: México los economistas del nacionalismo al neoliberalismo, México, FCE, 2003.

Banco Nacional de Comercio Exterior, México: la política económica del nuevo gobierno, México, [s. e.], 1971.

BARKer, TERry y Vladimiro Brailovsky, "La política económica entre 1976 y 1982 y el Plan Nacional de Desarrollo Industrial”, Investigación Económica, Facultad de Economía-UNAM, vol. XLII, núm. 166, octubre-diciembre de 1983, México.

Basáñez, Miguel, El pulso de los sexenios: 20 años de crisis en México, México, Siglo XXI, 1988.

y RoDeric Ai CAMP, "La nacionalización de la banca y la opinión pública en México", Foro Internacional, Colmex, vol. XXv, núm. 2, 1984, México, pp. 202-216.

BAZDresch, CARlos, "Reseña del libro de Carlos Tello, La nacionalización de la banca en México", El Trimestre Económico, FCE, núm. 206, abril-junio de 1985, México, pp. 616-629.

Bueno, Gerardo M. (coord.), Opciones de política económica en México después de la devaluación, México, Tecnos, 1977.

CÁRdenas, EnriQue, La política económica en México, 1950-1994, México, FCE, 1996.

EATWELL, JOHN y AJIT Singh, “¿Se encuentra 'sobrecalentada' la economía mexicana? Un análisis de los problemas de política económica a corto y mediano plazo”, Economía Mexicana. Análisis y Perspectivas, CIDE, núm. 3, 1981, México.

Elizondo Mayer-Serra, Carlos, "Los motivos de la nacionalización de la banca en México”, tesis de licenciatura, México, Colmex, 1987.

, La importancia de las reglas. Gobierno y empresarios después de la nacionalización bancaria, México, FCE, 2001.

Espinosa Rugarcía, Amparo y Enrique Cárdenas Sánchez (eds.), La nacionalización bancaria 25 años después, México, Centro de Estudios Espinosa Yglesias, tt. I y II, 2007.

Espinosa Yglesias, Manuel, BANCOMER. Logro y destrucción de un ideal, México, Planeta, 2000.

Flores de la Peña, Horacio, Teoría y práctica del desarrollo, México, FCE, 1976.

García Alba, PASCUAL, "Paradigmas y extremismos; los economistas mexicanos en el siglo XX”, Análisis Económico, UAM, vol. XVII, núm. 35, enero-junio de 2002, México, pp. 3-42.

y Jaime Serra Puche, Causas y efectos de la crisis económica en México, México, Colmex, 1984.

García Arias, Jorge, Economía política de la estabilidad cambiaria, Madrid, Consejo Económico y Social, 2002 (Colección Estudios, 135). 
Gracida Romo, Elsa M., "La década de 1970 en México: etapa de la transición del pensamiento económico" en María Eugenia Romero Sotelo (coord.), Historia del pensamiento económico en México. Problemas y tendencias (1982-2000), México, Trillas, 2005.

Granados Chapa, Miguel Ángel, La banca nuestra de cada día, México, Océano, 1982. HERnÁndez Rodríguez, Rogelio, Empresarios, banca y Estado. El conflicto durante el gobierno de José López Portillo 1976-1982, México, Flacso/Miguel Ángel Porrúa, 1988. IbARRA MuÑoz, DAVID, "Mercados, desarrollo y política económica: perspectivas de la economía de México" en Jorge Martínez Ríos, El perfil de México en 1980, México, Siglo XXI, 1970, pp. 89-199.

Lajous, Adrián, Mi cuarto a espadas, México, Edamex, 1985.

Looney, Robert, Economic Policymaking in Mexico. Factors Underlying the 1982 Crisis, Durham, Duke University Press, 1985.

López Portillo, José, Mis tiempos. Biografía y testimonio politico, México, Fernández Editores, 1988.

López Portillo Romano, José Ramón, Economic Thought and Economic Policy-Making in Contemporary Mexico: International and Domestic Components, Oxford, St. Anthony's College, 1994.

Love, JosePH L., Crafting the Third Wolrd: Theorizing Underdevelopment in Rumania and Brazil, Stanford, Stanford University, 1996.

Madrid, Miguel de la, Cambio de rumbo. Testimonio de una presidencia, 1982-1988, México, FCE, 2004.

Mancera Aguayo, Miguel, Inconveniencia del control de cambios, México, Banco de México, 1982.

Medina Peña, Luis, Hacia el nuevo Estado. México, 1920-1994, México, FCE, 1994.

Mirón, Rosa María y Germán Pérez, López Portillo: auge y crisis de un sexenio, México, UNAM, 1988.

Ortiz Mena, Antonio, El desarrollo estabilizador: reflexiones sobre una época, México, Fideicomiso Historia de las Américas-Serie Hacienda/ColmEX/FCE, 1998.

Packenham, Robert A., The Dependency Movement: Scholarship and Politics in Development Studies, Cambridge, Harvard University Press, 1992.

PÉREz LÓPEZ, ENRIQUe, Expropiación bancaria en México y desarrollo desestabilizador, México, Diana, 1987.

Rubli Kaiser, Federico, "Marco conceptual del enfoque monetario a la teoría de la macroeconomía abierta” en Federico Rubli y Benito Solís (comps.), México hacia la globalización, México, Diana Editorial, 1992.

Ruiz Durán, Clemente, 90 días de politica monetaria y crediticia independiente, México, BUAP/UNAM, 1984.

SAles Gutiérrez, CARlos, Indemnización bancaria y evolución del sistema financiero, 19821988, México, Páginas del Siglo XX, 1992. 
Secretaría de Patrimonio y Fomento Industrial, Plan nacional de desarrollo industrial, 1979-1982, México, s. e., 1979.

Secretaría de Programación y Presupuesto, Plan global de desarrollo 1980-1982, México, s. e., 1980.

Silva Herzog Flores, Jesús, A la distancia... Recuerdos y testimonios, México, Océano, 2007.

Solís, LeOpoldo, Economic Policy Reform in Mexico. A Case Study for Developing Countries, Nueva York, Pergamon Press, 1981.

SzÉKely, Gabriel, La economía politica del petróleo en México, 1976-1982, México, COLMEX, 1983.

Teichman, Judith, Policy Making in Mexico: From Boom to Crisis, Winchester, Allen \& Unwin, 1988.

Tello, Carlos, La política económica en México, 1970-1976, México, Siglo XXI, 1978. , La nacionalización de la banca en México, México, Siglo XXI, 1984.

Tinbergen, Jan, Economic Policy: Principles and Design, Amsterdam, North Holland, 1956.

UNIDAD DE LA CRÓNICA PRESIDENCIAL-PRESIDENCIA DE LA REPÚBLICA, Las razones y las obras. Gobierno de Miguel de la Madrid. Crónica del sexenio 1982-1988, primer año, México, Presidencia de la República, 1984.

Whitehead, Laurence, "The Economic Policies of the Echeverria Sexenio: What Went Wrong and Why", ponencia presentada ante la Latin American Studies Association, Pittsburgh, abril de 1979.

ZAID, GABRIEL, "Más progreso improductivo y un presidente apostador", Vuelta, núm. 73, diciembre de 1982, México. 